\title{
Developing Health Communication Materials During a Pandemic
}

\author{
Caroline Benski ${ }^{*}$, Aya Goto ${ }^{2}$, Creative Health Teams ${ }^{2}$ and Michael R. Reich ${ }^{3}$ \\ ${ }^{1}$ Takemi Program in International Health, Harvard T. H. Chan School of Public Health, Boston, MA, United States, ${ }^{2}$ Center for \\ Integrated Science and Humanities, Fukushima Medical University, Fukushima, Japan, ${ }^{3}$ Department of Global Health and \\ Population, Harvard T. H. Chan School of Public Health, Boston, MA, United States
}

\section{OPEN ACCESS}

Edited by:

Ayoub Bouguettaya, University of Birmingham,

United Kingdom

Reviewed by:

Samia Tasnim,

Texas A\&M University, United States

Merryn McKinnon,

Australian National University, Australia

${ }^{*}$ Correspondence:

Caroline Bensk

cbenski@hsph.havard.edu

Specialty section:

This article was submitted to Health Communication, a section of the journal

Frontiers in Communication

Received: 07 September 2020

Accepted: 28 October 2020

Published: 23 November 2020

Citation:

Benski C, Goto A, Creative Health

Teams and Reich MR (2020)

Developing Health Communication

Materials During a Pandemic

Front. Commun. 5:603656.

doi: 10.3389/fcomm.2020.603656
As the COVID-19 virus spread rapidly around the world, information related to the pandemic also spread quickly and in massive amounts. Uncertainty and unknowns about the pandemic together with the explosion of information created confusion and fear among many populations. A major challenge for public health practitioners is to provide clear and consistent messages that can be understood by different types of audiences, including vulnerable populations such as pregnant women and children who are often forgotten in this process. We compared and analyzed the development processes of health communication products for pregnant women in Madagascar and for elementary school children in Japan during the COVID-19 pandemic. This study compared these two field experiences in different socioeconomic settings to identify common strategies for the development of communication materials in a health crisis. The two cases both developed communication materials developed in collaboration with key local communicators and the target audiences. Both products used a simple and clear structure and included do's and don'ts. Messages were tailored toward the lifestyles of the target audience and phrased to fit with cultural and linguistic contexts. Both developer teams paid attention to easy-to-understand words and culturally accepted design and colors. The final products were distributed swiftly and widely through multiple channels with the local community. These two field experiences demonstrate common strategies for developing health communication materials that are culturally-tailored and visually-appealing in a timely manner and can be disseminated through existing channels in a health crisis. Our experiences emphasize that collaborative and iterative efforts based on an existing trust relationship with the target community can provide the foundation for a rapid communication response in a health crisis.

\section{Keywords: health communication, COVID-19, pandemic, health crisis, development process}

\section{HIGHLIGHTS}

- The COVID-19 pandemic produced a massive amount of information all around the world.

- A major public health challenge is to deliver health communication products with clear and simple messages during a health crisis and to reach all audiences, especially vulnerable populations.

- In this study, we compared and analyzed the development processes of two health communication products, one for pregnant women in Madagascar and one for elementary school children in Japan, during the COVID-19 pandemic. 
- We identified several common strategies for developing health communication materials in a crisis, despite very different country settings: the importance of developing and disseminating culturally-tailored and visually-appealing materials developed through collaborative and iterative processes with the target community.

\section{INTRODUCTION}

Health communication is a key factor that affects people's decision making to protect and promote health during a health crisis (Rudd et al., 2003; Goto, 2020). Developing appropriate communication materials can facilitate the behavior changes needed for each type of health crisis (e.g., evacuation after a nuclear accident, handwashing in a pandemic). This point is particularly important in the COVID-19 pandemic.

The COVID-19 pandemic has produced a global explosion of viral cases but also a massive and varied global explosion of information (Finset et al., 2020). People are overwhelmed by the volume and the viewpoints in COVID-19 information, through newspapers, social media platforms, and other new channels, making it difficult to distinguish which information is reliable and helpful and which is false and harmful. People feel confused about what to do and how to act, and may feel anxious and lost (Chater, 2020; Finset et al., 2020), which can lead to a secondary information disaster. The COVID-19 pandemic has heightened public uncertainty over many questions, in part due to our limited experience and knowledge about this novel virus (Chater, 2020). Addressing this uncertainty is a major challenge for health communicators involved with the COVID-19 virus.

In confronting this uncertainty, health communication materials need to create a space for interpreting and incorporating new scientific findings through multiple updates. This is a long and public learning process. Health communication does not end when materials are distributed to the target audience. Instead, communicators need to create a continuous learning process and use updates to solidify trust with the target audience. In these circumstances, public health institutions have a duty to contribute to the dissemination of concise and valid information in different contexts, to promote population well-being, and to give clear and consistent messages to people (Rudd et al., 2003). This learning process is especially important for vulnerable populations such as children and pregnant women, who are often forgotten in health communication (Dalton et al., 2020).

Yet little is written about how to develop communication materials during a health crisis. Tailored health educational materials are more effective than non-tailored ones (Sudo, 2011). But during a health crisis, when time and resources are extremely limited, we need additional strategies (Rudd and Baur, 2020). This commentary compares two health communication products about COVID-19 prevention in two very different socioeconomic settings-Madagascar and Japan-but with similar development approaches. Below, we first compare the development processes (from conceptualization to dissemination) for the two efforts. Then we examine how key messages were framed and adapted
TABLE 1 | Comparison of the two cases.

\begin{tabular}{|c|c|c|}
\hline & Case from Madagascar & Case from Japan \\
\hline Country setting ${ }^{*}$ & $\begin{array}{l}\text { Low-income setting } \\
\text { - GNI (PPP international \$): } \\
\text { 1,350 } \\
\text { - Probability of dying under } \\
\text { five (per 1,000 live } \\
\text { births): } 54 \\
\text { - Maternal mortality rate } \\
\text { (per } 100,000 \text { live } \\
\text { births): } 363\end{array}$ & $\begin{array}{l}\text { High-income setting } \\
\text { - GNI (PPP international \$): } \\
37,630 \\
\text { - Probability of dying under } \\
\text { five (per 1,000 live births): } 2 \\
\text { - Maternal mortality rate } \\
\text { (per 100,000 live births): } 5\end{array}$ \\
\hline Target population & Pregnant women & $\begin{array}{l}\text { Elementary school students } \\
\text { (10-12 years old) }\end{array}$ \\
\hline Literacy level & Low level or illiterate & Elementary school level \\
\hline Language & $\begin{array}{l}\text { French and Malgache (and } \\
\text { translated into multiple } \\
\text { languages for a wide } \\
\text { diffusion in Africa) }\end{array}$ & Japanese and English \\
\hline $\begin{array}{l}\text { Material types and } \\
\text { aims }\end{array}$ & $\begin{array}{l}\text { Two posters } \\
\text { - One for general } \\
\text { information on individual } \\
\text { protection and measures } \\
\text { - One to inform women } \\
\text { about "what to know" if } \\
\text { they are pregnant } \\
\text { regarding COVID-19 }\end{array}$ & $\begin{array}{l}\text { Two leaflets } \\
\text { - One for general } \\
\text { information on individual } \\
\text { protection and measures } \\
\text { - One to inform children } \\
\text { about how to enjoy life } \\
\text { during the } \\
\text { stay-home period }\end{array}$ \\
\hline
\end{tabular}

*Source: World Health Organization, https://www.who.int/countries/en/.

to meet the country-specific needs and contexts. Through this analysis, we identify three common strategies for developing health communication materials in a timely manner during a health crisis.

\section{DEVELOPMENT PROCESS: CONCEPTUALIZATION AND DISSEMINATION}

As shown in Table 1, the case settings in the two countries (Madagascar and Japan) are strikingly different in socioeconomic and health levels. But both cases involved health communication efforts focused on maternal and child health and targeted populations (mothers and children) with limited literacy. The health communication teams of the two countries worked independently, but through sharing experiences we found a number of commonalities. Such comparative case studies may enable us to replicate findings across different settings as well as to explore differences between the cases (Baxter and Jack, 2008).

In both conceptualization and dissemination, the development processes in these two efforts had various points in common (Table 2). First, plans to develop the communication materials were based on local needs identified through existing networks between professionals and communities. To accelerate development, the core content was drafted by health professionals utilizing materials that were already in use and wellaccepted. Revisions of these drafts were repeated in collaboration with key local communicators and the target audiences, and 
TABLE 2 | Common development processes in two countries: from conceptualization to dissemination.

\begin{tabular}{ll}
\hline Planning & - Local information needs were collected through existing networks \\
& between the professionals and community \\
- & Need for timely, accurate, and culturally appropriate health \\
& communication for the vulnerable groups was identified \\
- & Challenges existed in the mode of information distribution \\
& (printing and distribution difficulties in both local communities in \\
& Africa and schools in Japan) \\
Drafting & Information materials collected by health professionals \\
- & Utilized existing materials already tested or well-accepted \\
- & Focused not only on physical health, but also mental and social \\
& health \\
- Included a designer in the team & - Reviewed by local partners and the target audience \\
Reviewing & Review and revisions were done multiple times by both health \\
& professionals team and community partners \\
Distribution & Distributed in print and electronically at local institutes (health \\
& centers, hospitals, and schools) and public places \\
- Used existing professional networks and digital channels & (e-mails, webpages and SNS) \\
Revision & Kept revising the materials based on comments received while \\
& distributing \\
\hline & Clarified the date of updates as part of an ongoing process \\
\hline &
\end{tabular}

these iterative processes led to communication concepts shared by both professional and community perspectives.

Second, communication materials were distributed widely through multiple channels within the local community. Dissemination channels depended on the local context. In Madagascar, the posters were displayed on walls in health centers and in the main squares of the villages. In Japan, the leaflets were distributed to students on days that schools were open for a short time and posted on walls and webpages of the relevant schools. In order to facilitate distribution, the Japanese team collaborated with the municipal office and the board of education, which resulted in distribution at all schools in the region. Both developer teams also distributed an electronic version to health providers at local hospitals and municipalities for patients and community members.

\section{COMPARISON OF THE FINAL PRODUCTS: FRAMING AND ADAPTATION}

Both communication products used a simple and clear structure with $4-5$ sections (Figure 1 and Table 3 ). Messages were tailored toward the lifestyles of the target audience and their life environments. In both cases, the content focused on making clear messages including do's and don'ts and used one section to give information about additional resources. For Madagascar, the team used as few words as possible to make the product understandable by illiterate people. In Japan, the team focused on giving valid alternatives to children about how to spend time at home and in outside places instead of emphasizing the idea of social distancing which can be difficult for children to accept. This was an important discussion point during the development process, and we decided to list as many alternatives as possible even though it made the materials text-heavy. Both used reliable sources to give scientific legitimacy to the material (World Health Organization and Ministry of Health's recommendations for Madagascar; and Ministry of Health, Welfare and Labor and academic organizations for Japan). When facing a crisis, we are required to perform a quick search of generally reliable sources like the ones we used, including government and international, and professional organizations.

In both cases in Figure 1, there is a limited use of numbers. As shown in Table 3, both teams included a graphic designer and paid attention to easy-to-understand words and culturally accepted designs and colors, with many illustrations. Illustrations in Madagascar included women in their traditional clothing, and the Japanese materials included kanji (or characters) that children were used to reading. For Madagascar the posters used yellow and orange, while the Japanese material used traditional soft colors like blue and green. The messages were phrased to fit with cultural and linguistic contexts. For Madagascar "don't messages" were expressed clearly and related to the specific context: the material showed not to spit and stressed the avoidance of social gatherings through the image of a "taxi brousse." The Japanese material discretely mentioned the need to avoid stigmatizing patients, and showed how to sneeze into an elbow, which was a new practice for students.

\section{STRATEGIES FOR DEVELOPING COMMUNICATION MATERIALS IN A HEALTH CRISIS}

This comparison of communication products and processes in a health crisis led us to identify three common communication strategies.

\section{Strategy 1: Focus on Culturally-Adapted and Visually-Appealing Materials}

Public health communication interventions must capture the public's attention and convey messages in ways that are reliable and appropriate across languages, ages, cultural affiliations, and education levels for the target audience (Dowse et al., 2014; Adam et al., 2020). As shown in Tables 2, 3, the two health communication products described in this commentary had substantial differences, but both of them sought to make the materials culturally acceptable. The Madagascar materials used vivid colors and don't messages were stated explicitly, while the Japanese material used traditional soft colors and the don't messages were phrased implicitly. The Madagascar material showed not to spit, which was a common practice to avoid, whereas the Japanese material showed how to sneeze into an elbow, which was a new practice to apply. These adaptations of the general infection prevention measures were decided on through collaboration between the developer teams and the local communities in a process that continued throughout development and distribution.

These culturally tailored messages were shown visually with carefully selected images. Visual aids play a significant role in the front-line rapid responses to a health crisis, making these public health messages accessible to all in a timely manner. Past examples of images used in public health messages are the bold 

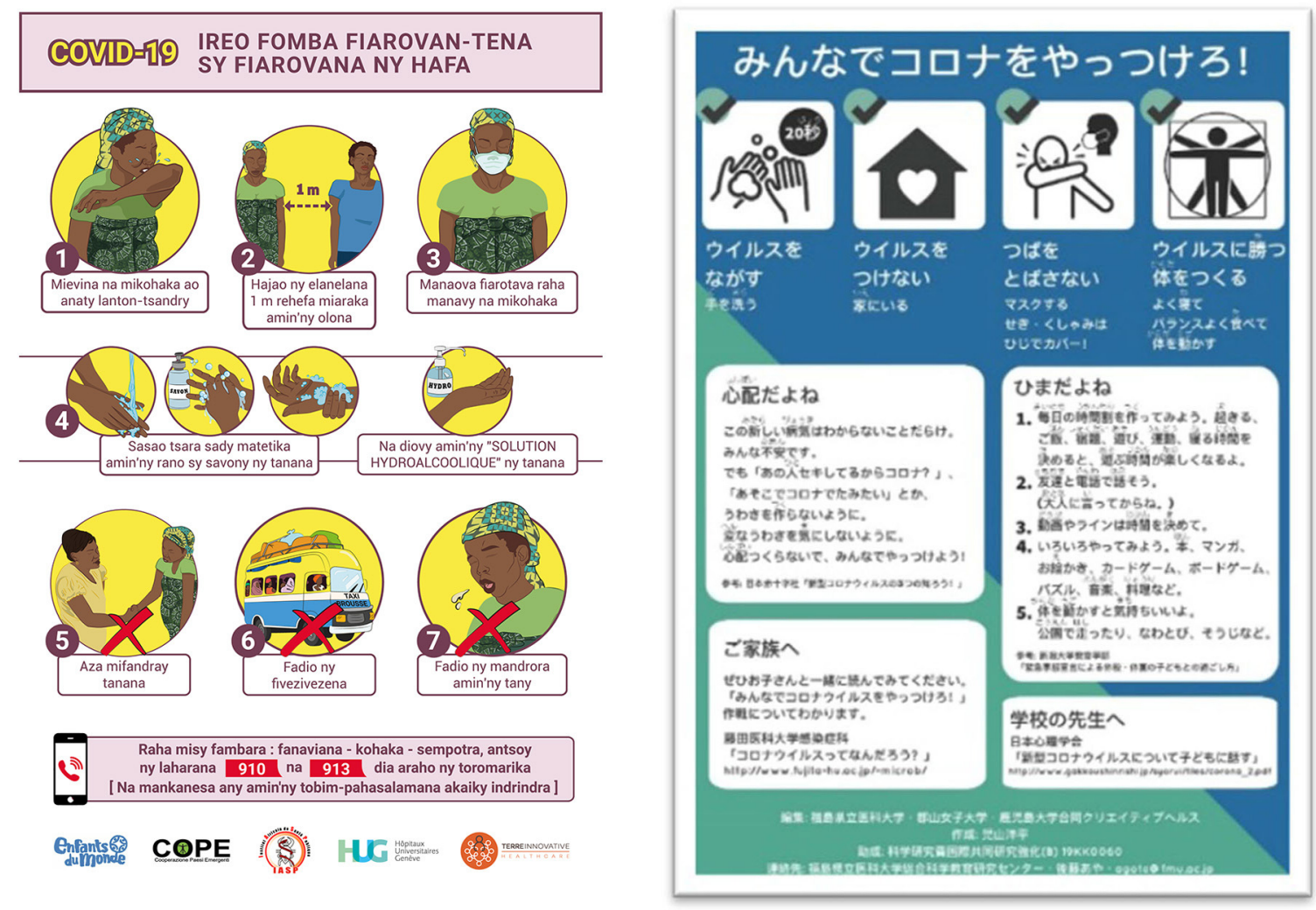

FIGURE 1 | Poster for pregnant women and Leaflet for children.

graphics used to raise awareness of HIV/AIDS in the 1980s and the health communication campaigns by non-governmental organizations during the 2014 and 2015 Ebola outbreaks ${ }^{1,2}$ (Kaaphen, 2020), as well as many other historical examples. ${ }^{3,4,5}$

\section{Strategy 2: Deliver Communication Products Quickly}

Both cases confronted challenges in deciding on the dissemination channels. Women in Madagascar, for example, had limited decision-making power to seek health information and even more restricted access to digital information. In Madagascar, communicating public health guidelines to the

${ }^{1}$ What Role Does Design Play in a Public Health Crisis? Eye on Design. (2020). Available online at: https://eyeondesign.aiga.org/what-role-does-design-play-ina-public-health-crisis/

${ }^{2}$ Discourse - Ebola poster Samba Cisse 2014. Calpol co-The Journal (2019). Available online at: https://calpolcothejournal.wordpress.com/2019/11/20/ discourse-ebola-poster-samba-cisse-2014/

${ }^{3}$ WWII Medical Posters by Abram Games. Europeana Pro. Available online at: https://pro.europeana.eu/data/wwii-medical-posters-by-abram-games (accessed May 2020).

${ }^{4}$ Otto and Marie Neurath Isotype Collection - Monoskop. Available online at: https://monoskop.org/Otto_and_Marie_Neurath_Isotype_Collection (access date May 2020).

${ }^{5}$ Toshokan. National Institute of Public Health in Japan. Available online at: Available online at: https://www.niph.go.jp/toshokan/koten/Statistics/jpg/ 10008882-p2.jpg community is challenging, as $90 \%$ of people do not use the internet, $60 \%$ do not have a radio, $61 \%$ do not have a mobile phone, and $25 \%$ of the adult population is illiterate ${ }^{6,7}$. In Japan, schools were closed during the early months of the pandemic in 2020, and teachers had limited opportunities to communicate with students and limited resources for printing and internet connection. Especially in Fukushima prefecture (where the Japanese project was based), only about $10 \%$ of the schools had a computerized education management system (the lowest in Japan according to a 2018 survey). ${ }^{8}$

Both cases confronted uncertainties in scientific knowledge but still decided to deliver public health communication products quickly, to provide the best-available information to the target audiences. Community members identified their needs, and

\footnotetext{
${ }^{6}$ Institut National de la Statistique - INSTAT/Madagascar, Programme National de lutte contre le Paludisme - PNLP/Madagascar, Institut Pasteur de Madagascar - IPM/Madagascar, ICF International. Enquète sur les indicateurs du paludisme 2016 Madagascar. Calverton, Maryland, USA: INSTAT, PNLP, IPM and ICF International (2017). Available online at: http://dhsprogram.com/pubs/pdf; https://dhsprogram.com/pubs/pdf/MIS23/MIS23.pdf

${ }^{7}$ Literacy rate, adult total (\% of people ages 15 and above) - Madagascar Data. Available online at: https://data.worldbank.org/indicator/SE.ADT.LITR.ZS? locations $=\mathrm{MG}$

${ }^{8}$ Ministry of Education, Culture, Sports and Technology. Education ICT Survey. Available online at: https://www.mext.go.jp/a_menu/shotou/zyouhou/ detail/1420641.htm
} 
TABLE 3 | Health information materials from the two cases: framing general protections measures in a country-specific context.

\begin{tabular}{|c|c|c|}
\hline & Poster for Madagascar Women & Poster for Japanese Children \\
\hline Structure & $\begin{array}{l}4 \text { areas } \\
\text { - Prevention do's } \\
\text { - Wash hands in detail } \\
\text { - Prevention don'ts } \\
\text { - Important phone numbers }\end{array}$ & $\begin{array}{l}5 \text { areas } \\
\text { - Prevention do's } \\
\text { - Stigma-related don'ts } \\
\text { - How to spend time at home } \\
\text { - Resources for parents } \\
\text { - Resources for teachers }\end{array}$ \\
\hline Content & $\begin{array}{l}\text { - Clear messages and avoided too much text } \\
\text { - } 7 \text { messages (maximum } 8 \text { messages were accepted) } \\
\text { - Included all prevention measures to protect women and their communities } \\
\text { following WHO recommendations and adapted to the context } \\
\text { - Used numbers to list the measures } \\
\text { - Included travels in "taxi brousse" rather than social gatherings in general } \\
\text { and local habits like spitting }\end{array}$ & $\begin{array}{l}\text { - Clear messages targeting children } \\
\text { - Balanced physical and mental health } \\
\text { - Included ways children can keep in touch with their peers rather } \\
\text { than stressing social distancing } \\
\text { - Limited the number of messages but showed many ways about } \\
\text { how to spend time at home } \\
\text { - Used and introduced reliable sources rather than creating } \\
\text { new ones }\end{array}$ \\
\hline Words & - Simple words and as few words as possible & $\begin{array}{l}\text { - Used words understandable to 4th graders } \\
\text { - Limit use of numbers } \\
\text { - Add how to read Kanji characters }\end{array}$ \\
\hline Design & $\begin{array}{l}\text { - Designed by a graphic artist } \\
\text { - Used illustrations of women with African physiognomy wearing clothes } \\
\text { (green tissues typical from traditional Madagascar) } \\
\text { - Adapted material already used by others for reproductive and maternal } \\
\text { health projects in Madagascar }\end{array}$ & $\begin{array}{l}\text { - Designed by a team member specialized in anthropology and } \\
\text { experienced in designing health information } \\
\text { - Followed Japanese schools' general style of handouts } \\
\text { - Designed for both print and digital distribution }\end{array}$ \\
\hline Illustrations & $\begin{array}{l}\text { - Included many illustrations to help illiterate women understand the } \\
\text { messages }\end{array}$ & - Used simple animated illustrations \\
\hline Colors & $\begin{array}{l}\text { - Made it colorful by using yellow, green, pink (representing women), red } \\
\text { (for don't), and blue }\end{array}$ & $\begin{array}{l}\text { - Checked previous studies on colors that Japanese children prefer } \\
\text { (blue and red) } \\
\text { - Avoided yellow and used green instead for children with autism } \\
\text { spectrum disorder }\end{array}$ \\
\hline Referral & - Included the emergency numbers to call if needed & $\begin{array}{l}\text { - Included messages for parents and teachers who support } \\
\text { children on a daily basis in order to work together against the } \\
\text { infection }\end{array}$ \\
\hline $\begin{array}{l}\text { Cultural adaptations } \\
\text { to context }\end{array}$ & $\begin{array}{l}\text { - Showed a "taxi brousse" (for African context) representing travel } \\
\text { conditions and crowded places } \\
\text { - Included "Do not spit" to avoid the commonly observed behavior }\end{array}$ & $\begin{array}{l}\text { - Added an illustration of sneezing into an elbow, which was a new } \\
\text { practice recommended in Japan after the COVID-19 pandemic }\end{array}$ \\
\hline
\end{tabular}

the health professionals selected the best available information. Cultural adaptation of the information was then done in an iterative manner involving both groups to decide on the final messages, images, and materials. In Madagascar dissemination started at the end of March 2020 and in Japan in April 2020. Based on past trust and collaboration, the community and the professional groups worked together to accelerate the development process to produce and disseminate the communication materials.

\section{Strategy 3: Use Existing Relationships of Collaboration and Trust}

Both cases decided to pre-test the information materials to assess audience perception, understanding, and socio-cultural acceptability, by using drafts with health workers and educators. Past studies show that once appropriate information is rolled out in communities, a shift in acceptance can occur regarding the prevalence of the infection and the adoption of positive behaviors $^{1}$ (Lucy Bray, 2016). Several recent reports examine collaborative information development in a clinical setting. As for the emergency settings, experiences from the Fukushima nuclear accident highlighted the importance of such collaboration from the acute phase onwards to minimize miscommunication in the longer term (Goto, 2020).

The main challenges of developing communication materials during a health crisis, such as the COVID-19 pandemic, are the limited time and resources, and the uncertainty of the risks. Finset et al. state that open, honest, consistent, specific and emotionally considerate information provision is important when facing the many uncertainties of the COVID-19 pandemic, but they do not explain "how" to do this. Our examples indicate that through a participatory approach, existing networks, and trust among stakeholders can be used in iterative processes of information development and revision to address uncertain risks in a health crisis. Our cases serve as practical examples of how professional-community collaboration can facilitate the development of health communication materials that are understandable to the public in the midst of a crisis. However, our case study lacks a rigorous formative assessment of how the materials influenced the target groups' knowledge, attitudes, and practices, which need to be explored in further research. Another point of concern is how to facilitate communication when a pre-existing close relationship does not exist. The previous example from the Fukushima nuclear accident recommends 
strategic implementation of the "multiple layers of translators" (Goto, 2020), in which scientific information is first provided to the key community workers who are close to the target audience, and then disseminated among their peers and a wider audience.

\section{CONCLUSION}

The major strength of this study is that we streamlined the development processes we usually use for health communication materials. The retrospective empirical nature of this study shows that in field practice sometimes the limited research rigor can be turned into strengths.

In this analysis we found striking similarities in the two development processes; these two field experiences in Madagascar and Japan shared three common strategies for developing communication materials in a health crisis; both cases developed culturally-tailored and visually-appealing materials in a timely manner and that were disseminated through existing channels. The two experiences show that collaborative and iterative efforts can provide the foundation for a rapid communications response in a health crisis. Such collaboration cannot be created instantly when a crisis occurs. Building these networks of trust between professionals and the community should be a basic principle of disaster preparedness.

\section{DATA AVAILABILITY STATEMENT}

The original contributions presented in the study are included in the article/supplementary material, further inquiries can be directed to the corresponding author/s.

\section{REFERENCES}

Adam, M., Bärnighausen, T., and McMahon, S. A. (2020). Design for extreme scalability: a wordless, globally scalable COVID-19 prevention animation for rapid public health communication. J. Glob. Health. 10:010343. doi: 10.7189/jogh.10.010343

Baxter, P., and Jack, S. (2008). Qualitative case study methodology: study design and implementation for novice researchers. Qual. Rep. 13, 544-559. https:// nsuworks.nova.edu/tqr/vol13/iss $4 / 2$

Chater, N. (2020). Facing up to the uncertainties of COVID-19. Nat. Hum. Behav. 4:439. doi: $10.1038 / \mathrm{s} 41562-020-0865-2$

Dalton, L., Rapa, E., and Stein, A. (2020). Protecting the psychological health of children through effective communication about COVID-19. Lancet Child Adolesc. Health. 4, 346-347. doi: 10.1016/S2352-4642(20)30097-3

Dowse, R., Barford, K., and Browne, S. H. (2014). Simple, illustrated medicines information improves ARV knowledge and patient self-efficacy in limited literacy South African HIV patients. AIDS Care 26, 1400-1406. doi: $10.1080 \% 2 \mathrm{~F} 09540121.2014 .931559$

Finset, A., Bosworth, H., Butow, P., Gulbrandsen, P., Hulsman, R. L., Pieterse, A. H., et al. (2020). Effective health communication - a key factor in fighting the COVID-19 pandemic. Patient Educ. Couns. 103, 873-876. doi: $10.1016 /$ j.pec.2020.03.027

Goto, A. (2020). Communicating with the public: lessons learned post disaster. J. Glob. Health Sci. 2:e6. doi: 10.35500/jghs.2020.2.e6

Kaaphen, M. (2020). Silence=Death-Project. NOMOI. Available online at: https:// nomoi.hypotheses.org/198

\section{AUTHOR CONTRIBUTIONS}

$\mathrm{CB}$ and $\mathrm{AG}$ contributed to the study design and to write the first draft. CHT contributed to the development of the health communication material and development process. MRR took part in the revision of the paper.

\section{FUNDING}

This study was supported by the Fund for the Promotion of Joint International Research (Fostering Joint International Research [B]) from the Japan Society for the Promotion of Science Grantsin-Aid for Scientific Research (No. 19KK0060).

\section{ACKNOWLEDGMENTS}

The Creative Health Team in Japan included the second author (AG) as PI, along with Yohei Koyama, Kenneth E. Nollet, Michio Murakami, and Yui Yumiya from Fukushima Medical University, Chihaya Koriyama from Kagoshima University, Satoko Okabe from Koriyama Women's University, Kazuki Yoshida from Iryo Sosei University and Alison Lloyd Williams from Lancaster University. For Madagascar, the team included the first author (CB) from Harvard T.H. Chan School of Public Health, Anna Valentino and Giovanna Stancanelli from Terre Innovative, Cecilia Capello and Nicole Curti Kanyoko from Enfants Du Monde, Adelia Soaroby from Ambanja District Hospital and Faly Razanalison from UNFPA Madagascar.

Lucy Bray, S. S. (2016). Developing an Information Leaflet for Children Having Planned Procedures in Hospital. Nursing Children and Young People. Available online at: https://journals.rcni.com/nursing-children-and-young-people/ developing-an-information-leaflet-for-children-having-planned-proceduresin-hospital-aop-ncyp.2017.e787

Rudd, R., Comings, J. P., and Hyde, J. N. (2003). Leave no one behind: improving health and risk communication through attention to literacy. $J$. Health Commun. 8(Suppl 1), 104-115. doi: 10.1080/713851983

Rudd, R. E., and Baur, C. (2020). Health literacy and early insights during a pandemic. J. Commun. Healthcare. 13, 13-16. doi: 10.1080/17538068.2020.1760622

Sudo, N. (2011). Developing an alcohol education leaflet for pregnant women using qualitative and quantitative data. Clin. Med. Insights Womens Health 4, 17-33. doi: 10.4137\%2FCMWH.S6541

Conflict of Interest: The authors declare that the research was conducted in the absence of any commercial or financial relationships that could be construed as a potential conflict of interest.

Copyright (C) 2020 Benski, Goto, Creative Health Teams and Reich. This is an openaccess article distributed under the terms of the Creative Commons Attribution License (CC BY). The use, distribution or reproduction in other forums is permitted, provided the original author(s) and the copyright owner(s) are credited and that the original publication in this journal is cited, in accordance with accepted academic practice. No use, distribution or reproduction is permitted which does not comply with these terms. 